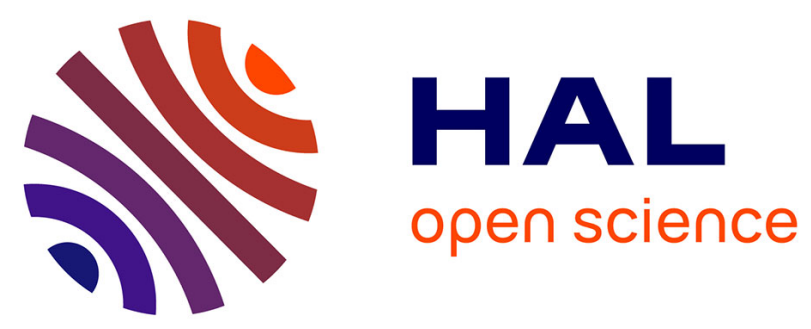

\title{
INVESTIGATION OF SOUND WAVES PROPAGATION PECULIARITIES IN GAS-LIQUID FOAM
}

\author{
I. Goldfarb, Z. Orenbakh, G. Shushkov, I. Shreiber, F. Vafina
}

\section{- To cite this version:}

I. Goldfarb, Z. Orenbakh, G. Shushkov, I. Shreiber, F. Vafina. INVESTIGATION OF SOUND WAVES PROPAGATION PECULIARITIES IN GAS-LIQUID FOAM. Journal de Physique IV Proceedings, 1992, 02 (C1), pp.C1-891-C1-894. 10.1051/jp4:19921194 . jpa-00251159

HAL Id: jpa-00251159

https://hal.science/jpa-00251159

Submitted on 1 Jan 1992

HAL is a multi-disciplinary open access archive for the deposit and dissemination of scientific research documents, whether they are published or not. The documents may come from teaching and research institutions in France or abroad, or from public or private research centers.
L'archive ouverte pluridisciplinaire HAL, est destinée au dépôt et à la diffusion de documents scientifiques de niveau recherche, publiés ou non, émanant des établissements d'enseignement et de recherche français ou étrangers, des laboratoires publics ou privés. 


\title{
INVESTIGATION OF SOUND WAVES PROPAGATION PECULIARITIES IN GAS-LIQUID FOAM
}

\author{
I.I. GOLDFARB, Z.M. ORENBAKH, G.A. SHUSHKOV, I.R. SHREIBER* and \\ FI. VAFINA \\ Institute of Northern Development, Siberian Branch USSR Academy of Sciences, 625003 Tyumen 3, \\ P.O. Bax 2774, USSR \\ *Ofakim Center of Technology, Ofakim 80300, P.O. Box 633, Israel
}

\begin{abstract}
$\begin{array}{lllllllllllll}\text { A } & B & S & T & R & A & C & T\end{array}$
Both theoretical and experimental results of sound waves propagation peculiarities investigation in gas-liquid foams are presented in the paper. It is shown that the results of the experiments on studying weak shock waves in the gas-liquid foam can not be satisfactorily described by the standard model of sound propagation in two-phase media. To explain the obtained experimental data the authors suggest the model considering the peculiarities of the foam structure and the presence of additional hydrodynamic mechanism, influencing the signal evolution in foam - liquid motion along the system of the Plateau-Gibbs channels. The data of the experimental and calculated profiles analysis are evidence of the fact that the suggested model describes the real acoustical properties of gas-liquid foams more precisely than certain models for the two-phase mixtures with small gas content.
\end{abstract}

1. Introduction.

In the experiments on studying the peculiarities of gas-liquid media acoustic properties of the bubbles structure [1] there were analyzed, as a rule, mixtures with small volumetric gas content. It can be explained by the difficulty to obtain the stable concentrated gas-liquid suspensions with closed to unity gas content because of the bubbles coagulation. The addition of a small portion of surface-active substances permits to stabilize mixture without changing the liquid viscosity and to define its acoustic properties with gas contents $\alpha_{2} \geq 0.9$. The present paper reflects the results of experimental investigations of acoustical oscillations propagation in a two-phase medium with gas content $\alpha_{2} \geq 0.9$. The results are compared with the model of sound propagation in foam, suggested by the authors.

Foam is according to the definition given in [2] a gas-liquid medium, consisting of the large number of gas bubbles separeted by thin liquid films. To characterize foams parameter $K$ - expansion factor is usually used because of great change in foam properties during small changes in volumetric gas content. This expansion factor is a ratio of foam volume $v_{0}$ to the liquid volume containing in it $V_{1} \quad\left(K=V_{0} / V_{1}\right)$ and is equal to the inverse moisture content $\left(K=1 / \alpha_{1}\right)$. 


\section{Experiment.}

The experimental plant presents a vertical shock tube of a standard configuration $[1,3]$. The pressure disturbance in it is initiated with the diaphragm break, separating the high pressure chamber from the working area. The pressure impulse initial amplitude depends on the diaphragm material. The working area is made of organic glass and supplied by 6 piesoelectric sensors placed at the interval of $0.05 \mathrm{~m}$. The distance from the diaphragm to the first sensor and from the last sensor to the bottom of the working area is more tham $1 \mathrm{~m}$ which helps to exclude the reflected waves from consideration.

The investigated medium is driven to the working area from the special foam generator, permitting to set expansion factor in wide diapason within the accuracy $5 \%$. The working area transparency allows to observe the process visually and to photograph foam.

Signals from sensors after processing are input into the computer, displayed at the colored monitor and recorded to the magnetic carrier for a long holding. The software gives the opportunity to read information from the magnetic disk, to print wave structures using a dot matrix printer and to calculate different acoustic characteristics.

\section{Results and Analysis.}

It is well known that sound attenuation in liquid with gas bubbles of small gas contents $\left(\alpha_{2}<<1\right)$ is caused mainly by the thermal dissipation [1]. As a result of heat transfer, the bubbles compression - expansion process becomes irreversible and acoustic wave energy is transformed into heat. At the low frequency region (where Peclet numbers are smaller than unity) this process intensity is inversely proportional to the gas thermometric conductivity coefficient. At the high frequency diapason (where Peclet numbers are larger than unity) the decrement of attenuation is directly proportional to the square root of this coefficient. The preceding experiments with low concentration bubbles suspensions of different gases prove to be valid to these theoretical assumptions. Helium bubbles cause considerably different wave attenuation than the air ones [1].

To ascertain the degree of interphase heat transfer influence on acoustic disturbances evolution in foam, the special experiments were conducted with foams containing gas phases, distinguished by their thermophysical properties: air, carbonic acid gas and helium.

In the experiments with all gas types non-linear effects like a slopping of the wave front propagating in the foam, were not registered. The display of sound velocity dispersion in the form of any oscillations was not also registered. Moreover, the initial pressure disturbance during the experiments comprises $3-10 \mathrm{kPa}$ which meets the condition $\Lambda \mathrm{P} / \mathrm{P}_{\mathrm{o}}<<1$ and there are reasons to consider the waves as linear. In its turn this allows us to use the notions of acoustics and to carry out the linear analysis of the formulated model.

To compare the experimental data with various models of sound propagation in foam [4,5] there have been used the method described breif ly in [3]. This method makes use of theoretical dispersion ratio and the procedure of fast Fourier transform. Fig. 1 can be given as an example of such experimental data and theoretical calculations comparison for the waves in aqua-helium foam. The analysis of Fig. 1 shows that the consideration of heat transfer processes only does not satisfactorily correlate theory and experiment. But including into the theoretical consideration the dissipation energy of the sound wave due to liquid motion along the channels allows to describe the experimental data with better accuracy. With the increase of 
foam expansion factor there can be observed the sufficient improvement of coincidence of theoretical and experimental profles. It may be explained by the fact that to calculate the liquid motion in foam the model suggested by the authors there have been used the polyhedral model of foam structure. By small expansion factor, foam's structure is spherical [2] and can not be described by the polyhedral model with the satisfactory degree of accuracy. With the growth of the expansion factor the foam structure approaches ideal polyhedral and the peculiarities of liquid motion in foam are better and better described by the suggested in [5] model. This results in the improving accuracy of description the experimental curves both for the aqua-air and the aqua-helium foam owing to the increase of the foam expansion factor in the model given in [5].

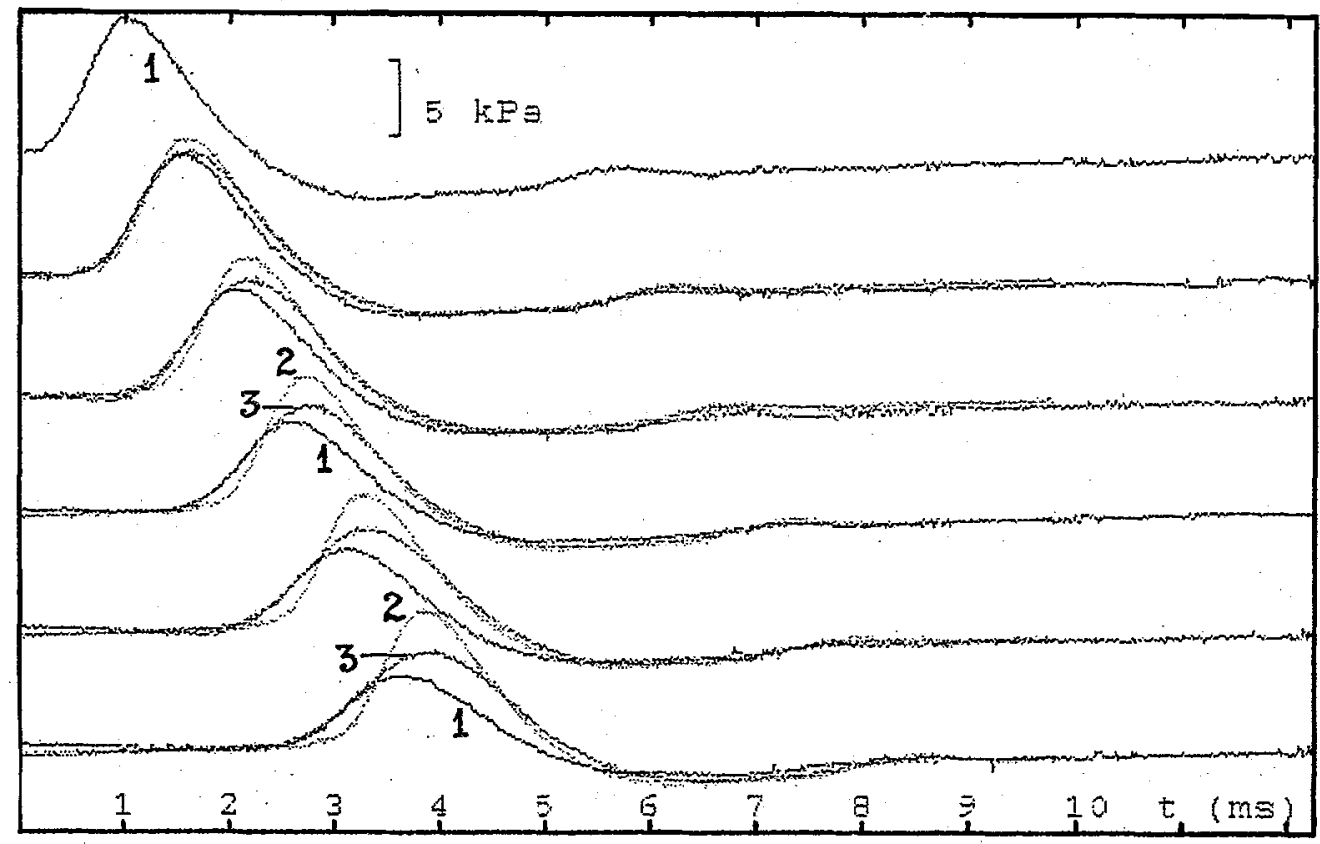

Figure 1. Comparison of theoretical and experimental data for the aqua-helium foam: 1 - means sensor data; 2 are calculation results without liquid motion; 3 - are calculation results with account of liquid motion. Foam parameters are the following: $\mathrm{K}=79, \mathrm{r}=0.08 \mathrm{~mm}$.

It is seen from Table 1 that the average experimental attenuation coefficient does not reveal the dependence on expansion factor both for aqua-air and aqua-helium foams. The comparison with the data in work [6] shows that average sound attenuation coefficient in foam is about six times higher than in two-phase bubble mixture with gas content $1 \%$. Moreover as it is seen from Table 1 the attenuation decrement for the aqua-helium foam is lower than for the aqua-air one at about $25-30 \%$. But if we proceed from the standard heat transfer model [1], the attenuation has to be minimized more sufficiently (because the bearing signal harmonics being obtained during the experiment lie in the low frequency diapason, where $P e<1$, but value of helium thermometric coefficient exceeds the value of this parameter for air more than an order). It testifies to that in the foam parameters and impulses frequencies diapason at which the experiment 
have been conducted $(30<\mathrm{K}<150,0.05 \mathrm{~mm}<\mathrm{r}<0.2 \mathrm{~mm}$, the bearing harmonics frequency $\leq 10001 / \mathrm{s}$ ) the heat transfer processes do not prevail over the determination of the peculiarities of the signal propagating in foam evolution.

Table 1. Comparison of attenuation decrement data for aqua-air and aqua-helium foams.

\begin{tabular}{|l|c|c|c|c|}
\hline Expansion factor & 33 & 44 & 58 & 79 \\
\hline $\begin{array}{l}\text { Attenuation coefficient } \\
\text { in aqua-air foam (1/m) }\end{array}$ & 3,75 & 3,70 & 3,18 & 3,08 \\
\hline $\begin{array}{l}\text { Attenuation coefficient } \\
\text { in aqua-helium foam (1/m) }\end{array}$ & 2,68 & 2,57 & 2,69 & 2,58 \\
\hline
\end{tabular}

4. Conclusion.

The analysis of the obtained data and their comparison with various theoretical models of sound propagation in foam [4,5] permit to make the following conclusion. The generally accepted approach to the description of the sound wave energy dissipation in the two-phase medium [4] does not permit to describe the results of the experiments on weak shock waves propagation in the foam with the satisfactory accuracy. The introduction into theoretical model the processes of liquid motion along the Plateau-Gibbs channels system (the detailed description of the model is given in the work [5]), allows to describe the gas-liquid foam acoustical charachteristics suffisiently more precisely.

\section{R E F E R E N C E S}

1. Wijngaarden L., van. Propagation of Shock Waves in Bubble Liquid Mixtures. - In: Progress in Heat and Mass Transfer. Oxf ord e.a.,1972,vol.2,pp.637-649.

2. Manegold E. Schaum. - Heidelberg, Center, 1953, 512p.

3. Orenbakh Z.M.. Shreiber I.R., Shushkov G.A. Pressure Waves Propagation in Gas - Liquid Foam. - In: Physical Acoustics: Fundamentals and Applications. New-York, Plenum Publishing Corporation, 1991, pp.563-567.

4. Shagapov V.Sh. The Influence of Heat Transfer Processes between Phases on Small Disturbances Propagation in Foam. Thermophysics of Hihg Temperature (USSR), 1985, V.23, N1. pp. 729-735.

5. Goldfarb I.I., Shreiber I.R., Vafina F.I. The Influence of Heat Transfer and Liquid Flow on Sound Propagation in Foam. - In: Physical Acoustics: Fundamentals and Applications. New-York, Plenum Publishing Corporation, 1991, pp.341-346.

6. Kuznetzov V.V., Nakoryakov V.E., Pokusaev B.G., Shreiber I.R. Propagation of Perturbation in Gas - Liquid Mixture. J. of Fluid Mech., 1978, vol.85, N4, pp. 85-96. 